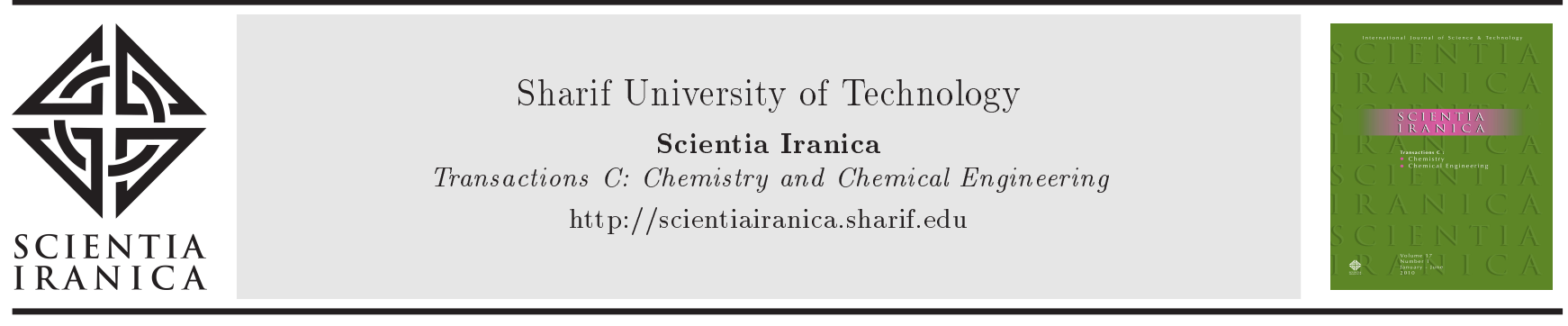

\title{
Reactive extraction of lactic acid using environmentally benign green solvents and a synergistic mixture of extractants
}

\section{A. Kumar and A. Thakur*}

Research Laboratory-III, Department of Chemical Engineering, Sant Longowal Institute of Engineering and Technology, Longowal148106, Punjab, India.

Received 13 November 2018; received in revised form 7 June 2019; accepted 14 September 2019

\author{
KEYWORDS \\ Green solvents; \\ Synergistic mixture of \\ extractants; \\ Distribution \\ coefficient $\left(K_{D}\right)$; \\ Reactive extraction; \\ Lactic acid.
}

\begin{abstract}
An environment-friendly reactive extraction method as a novel phase separation technique is considered to extract Lactic Acid (LA) from the aqueous solution by means of environmentally benign green diluents along with a synergistic mixture of extractants. Reactive extraction of LA was carried out through a synergistic mixture of extractants (trioctylamine (TOA), Aliquat336, and tridodecylamine (TDDA)), organic solvents, and non-toxic and biocompatible green diluents. According to the various investigated LA reactive extraction processes, the process featuring sunflower oil, synergist extractant (TOA and Aliquat336), and Butan-2-ol was found to be the most favorable system. The LA distribution coefficient $\left(K_{D}=27.75 \pm 0.22\right)$ and extraction efficiency $(\eta=97.17 \pm 0.54 \%)$ were obtained by a system consisting of LA concentration $(0.05[\mathrm{M}])$, TOA (15\%, v/v), Aliquat336 (15\%, v/v), phase ratio (1:1, v/v), solvent ratio (2.5, v/v), agitation speed $(100 \mathrm{rpm})$, and stirring time $(120 \mathrm{~min})$. The main driving force for this research work on the LA reactive extraction from the aqueous solution is the development of a suitable combination of extractants, organic solvents, and natural solvents that possesses high affinity with LA and, also, has lower toxicity with respect to LA-producing microbes. (C) 2019 Sharif University of Technology. All rights reserved.
\end{abstract}

\section{Introduction}

The demand for Lactic Acid (LA) is increasing day by day at a very fast rate in several industrial areas. LA is a sugar-based chemical and is applicable both to food and various non-food industries, such as cosmetic (as a moisturizer) and pharmaceutical (for making parental solutions) industries, so as to produce chemicals (oxygenated) as plant growth regulators and special chemical intermediates [1-4]. In addition, it (as Poly-Lactic Acid (PLA)) has gained

*. Corresponding author. Tel.: +9101672 253321

E-mail address: avin_thakur2@yahoo.com (A. Thakur)

doi: $10.24200 /$ sci.2019.52233.2610 much attention in the polymer sector as a monomer for producing biodegradable and environment-friendly plastics [5]. Recently, the development of sustainable recovery/separation techniques for the bio-based LA has received an ample deal of consideration to decrease reliance on petroleum-based organic solvents. The production cost of LA is mainly dominated by its downstream processing cost, which involves 30 to $40 \%$ of the total LA production costs [6]. Therefore, the progress of competitive and economic techniques of product (LA) separation and purification from the aqueous waste streams and from the fermentation broth has become the recent focus of research from both the environmental and economic points of view $[7,8]$. The industrial and traditional technique of LA separation is precipitation, which uses calcium hydroxide and 
large amounts of sulfuric acid and further produces solid waste, i.e., calcium sulfate (environmentally unfriendly) as a by-product [8,9]. In order to reduce the cost, various extraction methods (such as adsorption [10], membrane separation [11,12], electrodialysis [13,14], ultrafiltration [15], and extraction [16,17]) have efficaciously been applied to the extraction of LA. All these methods possess several specific disadvantages (such as poor extraction efficiency (\%), being uneconomical, the generation of huge amount of wastewater, high complexity, high energy consumption, and large production of by-products) [13]. Among all of the aforementioned techniques, reactive extraction has been considered as one of the best options for these conventional methods due to its various merits such as ensuring a high-purity product with minimum cost, being comparatively efficient and cheap while requiring a relatively short amount of processing time, being easy to scale up, being environmentally safe, high selectivity, and increasing the recovery by using a combination of extractants, organic solvents, and natural non-toxic solvents $[8,18]$.

To date, on an industrial scale, most of the LA reactive extraction techniques use only Petroleumbased Organic Solvents (POSs) (such as alcohols, ethyl acetate, and aliphatic hydrocarbons), which are found to be unsuitable for LA recovery from the diluent aqueous streams (low in concentration) due to very high affinity of LA with water molecules (i.e., hard to isolate), giving a low distribution coefficient $[7,8]$. The high cost of these POSs, toxicity, poor process safety, non-renewability, non-biodegradability, environmental pollution problems during solvent regeneration, flammability, depletion of world petroleum reserves, undesirable influence on the activities of biochemical substances (such as microbes), and the pertinent progress of environmentally benign technologies have been considered in the dynamic research on environmentally benign green solvents for the separation and purification of LA from the aqueous solution [7,19]. In these years, a large reduction in the use of organic diluents from the industrial processes and their substitution by the environmentally benign green solvents (vegetable oils) have been intensively investigated [20]. The use of such a type of green solvents during the formulation of organic phase helps make industrial processes more environmentally benign and decrease the amounts of hazardous wastes [21]. The application of green solvents (such as sunflower oil, soya bean oil, cottonseed oil, palm oil, til oil, rice bran oil, mustard oil, olive oil, etc.) during the organic phase formulation has been continuously grasping the attention of researchers and scientists across the world as a better alternative to these POSs [21]. These green solvents enjoy several pertinent physiochemical characteristics such as renewability, being economical, eco- friendliness, non-volatility, biodegradability, being nonpolluting, being easy to recoverable, and viscous nature (kinematic viscosity $=30-40 \mathrm{cSt}$ at $38^{\circ} \mathrm{C}[20]$ ) $[22,23]$.

The amine-based extractants (trioctylamine (TOA), tridodecylamine (TDDA), and Aliquat336) during the reactive extraction of carboxylic acids from aqueous solution and the dilute waste solution provide very high values of distribution coefficient [8,24]. The application of a single extractant during the solute extraction has suffered from such limitations as poor loading capacity of solute molecules into the organic phase. Therefore, a combination of various extractants is applied to the reactive extraction systems for obtaining enhanced extraction efficiency (\%) owing to the synergistic effect of extractants [18,24]. Essentially, synergism is a collaboration of two extractants/carriers that further facilitates the transportation of solute from the aqueous to organic phase. Recently, the applications of a synergistic mixture of extractants during the various extraction studies have been observed [19,23,25-29]. Organic solvents have good influence on the extraction power of these extractants, reaction stoichiometry, and good solvation for the acid-amine complex. Therefore, these organic solvents should be used along with the green solvents and extractants for obtaining the highest achievable extraction efficiency (\%). In this present investigation, reactive extraction was recommended for separating LA from the aqueous solution by means of environmentally benign green solvents, a synergistic mixture of extractants, and organic solvents. Firstly, the effects of various organic and green diluents on the LA distribution coefficient were investigated. Secondly, the individual and synergistic effects of various extractants (TOA, TDDA, and Aliquat336) on LA distribution coefficient were investigated.

\section{Extraction methodology}

\subsection{Materials and methods}

All the reagents were of analytical grade and used without any further treatment. TOA and TDDA were procured from the MERCK, Pvt Ltd, India. Aliquat336 was used as an extractant and purchased from S.D. Fine-Chem. Ltd, India. Lactic acid and organic solvents (butan-2-ol, 1-decanol, ethyl acetate, hexane, heptane, and 1-octanol) were supplied by S.D. Fine-Chem. Ltd, India. All the vegetable oils (refined) were used as environmentally benign green solvents and procured from the local market. Phenolphthalein was used as an indicator and procured from LOBA Chemie, Pvt Ltd, India.

\subsection{Experimental procedure}

All the extraction experiments were conducted in a temperature-controlled incubator (new Brunswick TM 
Table 1. Experimental conditions and holding values of the LA reactive extraction.

\begin{tabular}{clccc}
\hline \multicolumn{5}{c}{ Experimental conditions for LA reactive extraction } \\
\hline S. no. & Variables & Range & Units \\
& & low $(-)$ & high $(+)$ & \\
1 & LA concentration & 0.05 & 0.2 & {$[\mathrm{M}]$} \\
2 & Phase ratio (EP: OP) & 0.5 & 4 & $\mathrm{v} / \mathrm{v}$ \\
3 & Solvent ratio (BU: SU) & 0.11 & 10 & $\mathrm{v} / \mathrm{v}$ \\
4 & Solvent ratio (BU: SU) with extractants & 0.16 & 7 & $\mathrm{v} / \mathrm{v}$ \\
& & Holding values & & \\
5 & Stirring speed & 100 & & $\mathrm{rpm}$ \\
6 & Stirring time & 120 & $\mathrm{~min}$ \\
7 & Phase separation time & 30 & $\mathrm{~min}$ \\
8 & Temperature & 25 & \\
\hline
\end{tabular}

${ }^{a}$ EP: External Phase; OP: Organic Phase;

b BU: Butan-2-ol; SU: Sunflower oil.

Innova ${ }^{\circledR}$ 40) at a constant temperature of 298.15 $K$. The aqueous solutions of LA with various desired concentrations were made by dissolving liquid LA in Millipore Milli-Q deionized water (MERCK Millipore filtration). All the aqueous solutions were homogenized and uniformly mixed. The organic phase of volume $10 \mathrm{~mL}$ was made of various extractants (TOA, TDDA, and Aliquat336), organic solvents, and environmentally benign green solvents. Both of the phases at different phase ratios were intermixed in an Erlenmeyer or conical flask and shaken at a stirring speed of $100 \mathrm{rpm}$ for two hours to gain the extraction equilibrium. Then, the solution was placed in the test tubes for settling and exact phase separation of both phases. After the settling of solution, two phases (organic phase (top phase) and aqueous phase (bottom phase)) were formed, and the concentration of LA in the aqueous phase was determined through acid-base titration and reconfirmed by a colorimetric method by using UV/VIS- spectrophotometer (model DR 5000 $\mathrm{HACH}, \mathrm{USA}$ ) [30]. The organic phase concentration was calculated by the materials balance. The various experimental conditions and holding values for LA reactive extraction are shown in Table 1.

\section{Theory of reactive extraction of LA}

The reaction mechanism of LA reactive extraction contains two phases (aqueous phase and organic phase). The main step during the LA reactive extraction is the formation of complexes $\left(R_{3} N: H L A\right.$ and $R_{4} N H^{+} X^{-}$: $H L A)$, composed of the LA molecule and a complexing reactant. These complexes are soluble in the organic phase. The synergist extractant (TOA and Aliquat336) makes complexes with the solute molecule (lactic acid having the lactic acid formula as $H L A$ ) during the transportation of LA from aqueous solution to the organic solution $[25,26]$. The schematic representations of the physical and reactive/chemical extraction of LA from the external feed phase using complexing reactants along with the major reactions are shown in Figure 1. The complex formation reactions are reversible in nature, as shown in Figure 1 . The physical interaction with the diluents (organic solvents and natural solvents) can be represented by the undissociated ( $H L A)$ molecule of LA:

$$
[H L A]_{\text {aq. }} \leftrightarrow[H L A]_{\text {org. }},
$$

where $[H L A]_{o r g}$. and $[H L A]_{a q}$. represent the concentration of LA, which is transferred to the organic phase by the physical interaction of diluents, and the concentration of un-dissociated LA in the aqueous solution [24]. The $\mathrm{pH}$ of LA aqueous solution was kept constant near its acid dissociation constant $\left(p K_{a}=\right.$ 3.86 ) due to $\mathrm{pH}$ greater than $p K_{a}$ and more dissociation of acid molecules occurring, which further reduced distribution coefficient and, thus, decreased the extraction efficiency $(\%)[31,32]$. The LA distribution coefficient $\left(K_{D}\right)$ and extraction efficiency $(\eta, \%)$ can be obtained through Eqs. (2), (3), and (4) [33]:

$$
\text { Distribution coefficient }\left(K_{D}\right)=\frac{[H L A]_{\text {org }}}{[H L A]_{\text {aq }}} \text {, }
$$

Extraction efficiency $(\eta, \%)=\frac{K_{D} \times 100}{1+K_{D}}$

Extraction efficiency $(\eta, \%)=$

$$
\frac{V_{0} \times[H L A]_{a q .}-V_{e q .} \times[H L A]_{o r g .}}{V_{0} \times[H L A]_{a q .}}
$$

where $V$ is the volume of the aqueous phase, subscript 0 is the initial condition, while $e q$. is the condition in equilibrium. 


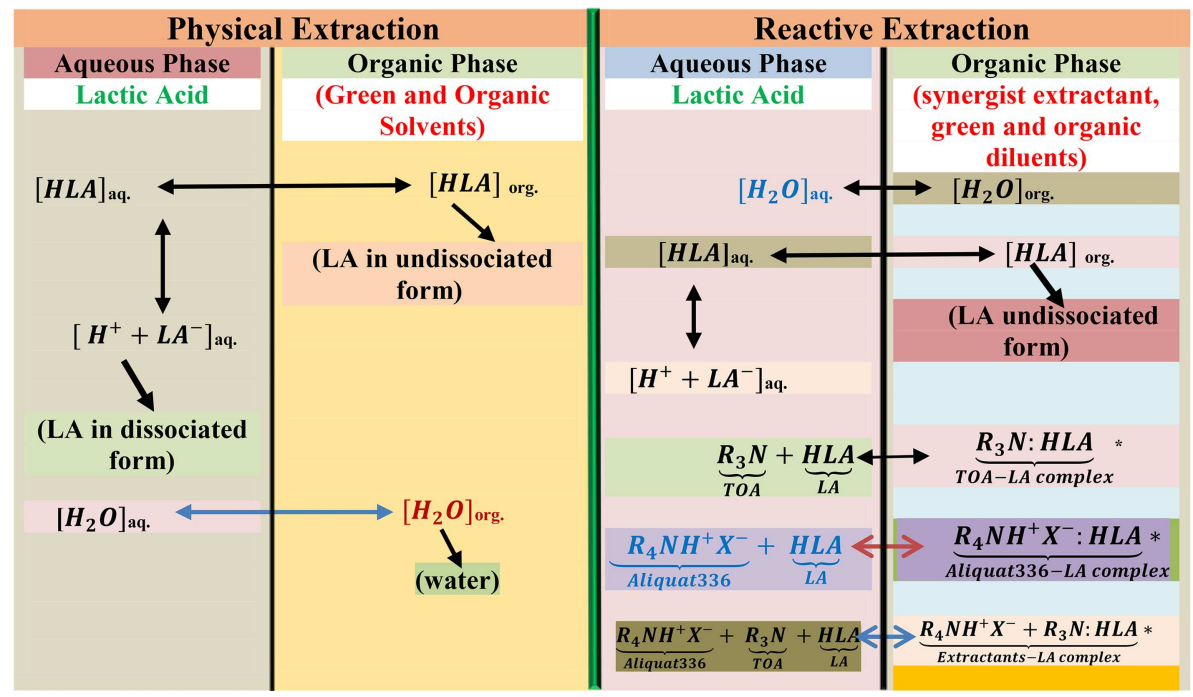

Figure 1. Schematic illustration of the physical and reactive extraction process of LA transportation from aqueous solution. [Experimental conditions: LA concentration: 0.05 [M], phase ratio: 1:1 (v/v), agitation time: 120 min, stirring speed: $100 \mathrm{rpm}$, temperature: $25^{\circ} \mathrm{C}$, phase separation time: $30 \mathrm{~min}$, feed phase volume: $10 \mathrm{~mL}$, and organic phase volume: $10 \mathrm{~mL}(70 \%($ butan-2-ol $(50 \%(\mathrm{v} / \mathrm{v}))+$ sunflower oil $(20 \%(\mathrm{v} / \mathrm{v})))+30 \%(\mathrm{v} / \mathrm{v})$ synergist extractant $(\mathrm{TOA}(15 \%(\mathrm{v} / \mathrm{v}))+$ Aliquat336 $(15 \%(\mathrm{v} / \mathrm{v})))]$. ${ }^{*}$ Reactions take place at interface between aqueous and organic phases.

\section{Results and discussion}

\subsection{Physical extraction of $L A$}

The mechanism of LA physical extraction (as shown in Figure 1) consists of two phases: aqueous phase and organic phase. The separation during the physical extraction of LA is mainly based on the relative solubility of the solute molecules between the two different phases. During this process, the transportation of LA molecules from the aqueous to organic phase takes place until the thermodynamic equilibrium in the multiphase system is reached [8,26]. The main purpose of performing the physical extraction of LA is to deter mine the influence of various organic diluents and green diluents on the LA distribution coefficient $\left(K_{D}\right)$. In the case of physical extraction, LA distribution coefficient $\left(K_{D}\right)$ is defined as the ratio of the concentration of the extracted solute molecule to the aqueous phase acid concentration.

\subsubsection{Effect of different organic solvents on the $L A$ distribution coefficient $\left(K_{D}\right)$}

The effect of different organic solvents (butan-2-ol, 1decanol, ethyl acetate, heptane, hexane, and 1-octanol) on $K_{D}$ for various feed phase concentrations (as given in Table 1) in the aqueous solution is elucidated in Figure 2. These organic solvents (in the pure form) exhibit a very low value of distribution coefficient since the LA has high affinity with water, making it hard to isolate. Therefore, physical extraction with conventional solvents is not suitable for the recovery of LA since it gives a poor LA distribution coefficient as compared to reactive extraction [16]. The loading

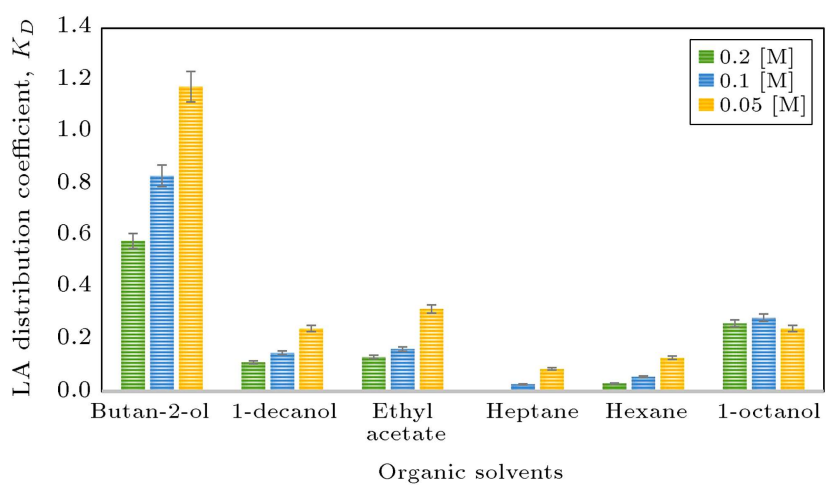

Figure 2. Effect of various organic solvents on the LA distribution coefficient $\left(K_{D}\right)$. [Experimental conditions: LA concentration: $0.2,0.1$, and $0.05[\mathrm{M}]$, phase ratio: $1: 1$ (v/v), agitation time: $120 \mathrm{~min}$, stirring speed: $100 \mathrm{rpm}$, temperature: $25^{\circ} \mathrm{C}$, phase separation time: $30 \mathrm{~min}$, feed phase volume: $10 \mathrm{~mL}$, and organic phase volume: $10 \mathrm{~mL}$ organic diluent].

rate of these organic solvents mainly depends on the equilibrium solubility and donor bonds [34]. Among all the organic solvents, Butan-2-ol gives the highest value of distribution coefficient $\left(K_{D}=1.175 \pm 0.05\right)$ for the LA concentration of $0.05[\mathrm{M}]$.

Hexane $\left(K_{D}=0.13 \pm 0.002\right)$ and heptane $\left(K_{D}=\right.$ $0.0875 \pm 0.0005)$ both give a very low value of LA distribution coefficient $\left(K_{D}\right)$ for the LA concentration of $0.05[\mathrm{M}]$ since they are non-polar in nature, leading further to the very poor solvation of the formed complex. The LA distribution coefficients $\left(K_{D}\right)$ in the case of pure diluents were found to be in order of alcohols (butan-2-ol, 1-decanol, and 1-octanol) > ester 
(ethyl acetate) $>$ alkane (hexane and heptane) [33]. Polar diluent (butan-2-ol) gives a high value of distribution coefficient or a high extraction rate since it can stabilize the ion-pair formed by hydrogen bonds or by solvation [16]. Butan-2-ol is a polar protic solvent characterized by a high value of dielectric constant (16.54 represents the solvent-solute local interaction and solute solvation by solvent or extractant) and low solubility $(290 \mathrm{~g} / \mathrm{l})$ in water. In the case of polar solvents, $K_{D}$ enhances with a rise in polarity of the solvent since they are capable to form hydrogen bonds [35]. The reactive extraction of LA from aqueous solution was also carried out by using $n$-butanol as an organic solvent by Chawong and Rattanaphanee [36].

\subsubsection{Effect of different natural solvents on the $L A$ distribution coefficient $\left(K_{D}\right)$}

The value of $K_{D}$ for various natural solvents (such as mustard oil, cottonseed oil, rice bran oil, til oil, soya bean oil, sunflower oil, and olive oil) for different aqueous-phase LA concentrations is shown in Figure 3.

Among all, cottonseed oil $\left(K_{D}=0.298 \pm 0.003\right)$ and sunflower oil $\left(K_{D}=0.191 \pm 0.004\right)$ give the highest value of distribution coefficient for the 0.05 [M] aqueous-phase concentration of LA. The environmentally benign green solvents (or vegetable oils) are cheap and non-toxic and have a less environmental impact, but give a very low value of distribution coefficients due to their poor solvation power [37]. However, these natural solvents can be helpful in reducing toxicity of the extractants and organic solvents by dissolving the water-soluble toxic part of the extractants since these in-situ extractants (on site or in position) are very toxic toward LA-producing microorganisms because they break the cell membrane of the microorganisms, causing metabolite (intermediate product of metabolic reaction) to come out [38].

\subsection{Reactive extraction of $L A$}

\subsubsection{Effect of various extractants on the $L A$ distribution coefficient $\left(K_{D}\right)$}

From Figures 1 and 2, it is very well explained that the LA physical extraction along with the organic solvents and natural solvents gives a very poor LA distribution coefficient. To increase the LA distribution coefficient, it is suggested that the application of different extractants ((TOA) (tertiary amine and non-polar in nature), (TDDA), and trioctyl methylammonium chloride (Aliquat336)) plays a very vital role in LA recovery. During this investigation, the organic phase is composed of green solvents, organic solvents, and extractants. The effect of various extractants on $K_{D}$ is depicted in Figure 4. TOA along with mustard oil shows a maximum value of $K_{D}\left(K_{D}=0.277 \pm\right.$ $0.004)$; Aliquat336 along with cottonseed oil gives the maximum value of LA distribution coefficient $\left(K_{D}=\right.$ $0.27 \pm 0.0034)$; TDDA along with rice bran oil gives the maximum value $K_{D}\left(K_{D}=0.129 \pm 0.003\right)$. Both sunflower oil and soya bean oil have shown the maximum value of $K_{D}\left(K_{D}=0.128 \pm 0.0012\right.$ for sunflower oil and $K_{D}=0.218 \pm 0.0014$ for soya bean oil) along with Aliquat336 [26]. TOA is a solvating extractant (meaning the competition for water in interaction with the solute molecules) that forms a water-insoluble complex with solute molecules. Aliquat336 works as an ion-exchanger, in which chloride ion is exchanged with the anion of the acid (lactate anion, $\mathrm{A}^{-}$) [38].

These extractants should be used in a low con-

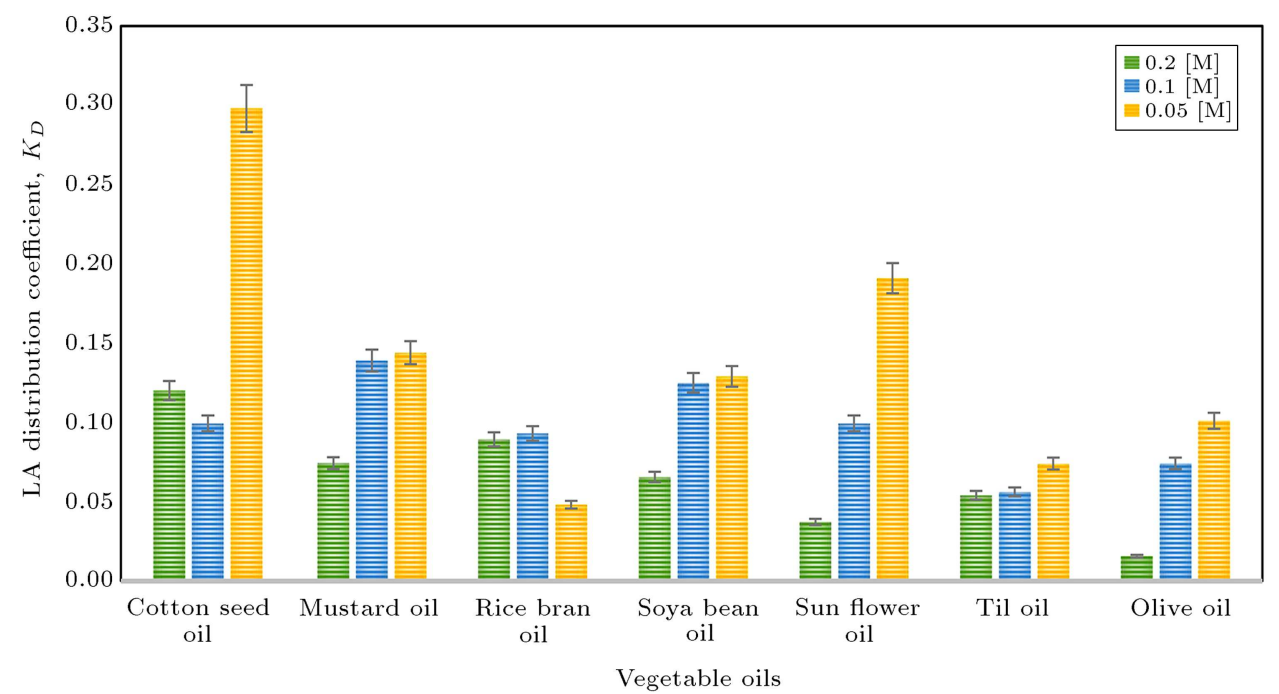

Figure 3. Effect of natural solvents (or vegetable oils) on the LA distribution coefficient $\left(K_{D}\right)$. [Experimental conditions: LA concentration: $0.2,0.1$, and $0.05[\mathrm{M}]$, phase ratio: $1: 1(\mathrm{v} / \mathrm{v})$, agitation time: $120 \mathrm{~min}$, stirring speed: $100 \mathrm{rpm}$, temperature: $25^{\circ} \mathrm{C}$, phase separation time: $30 \mathrm{~min}$, feed phase volume: $10 \mathrm{~mL}$, and organic phase volume: $10 \mathrm{~mL}$ green diluent]. 


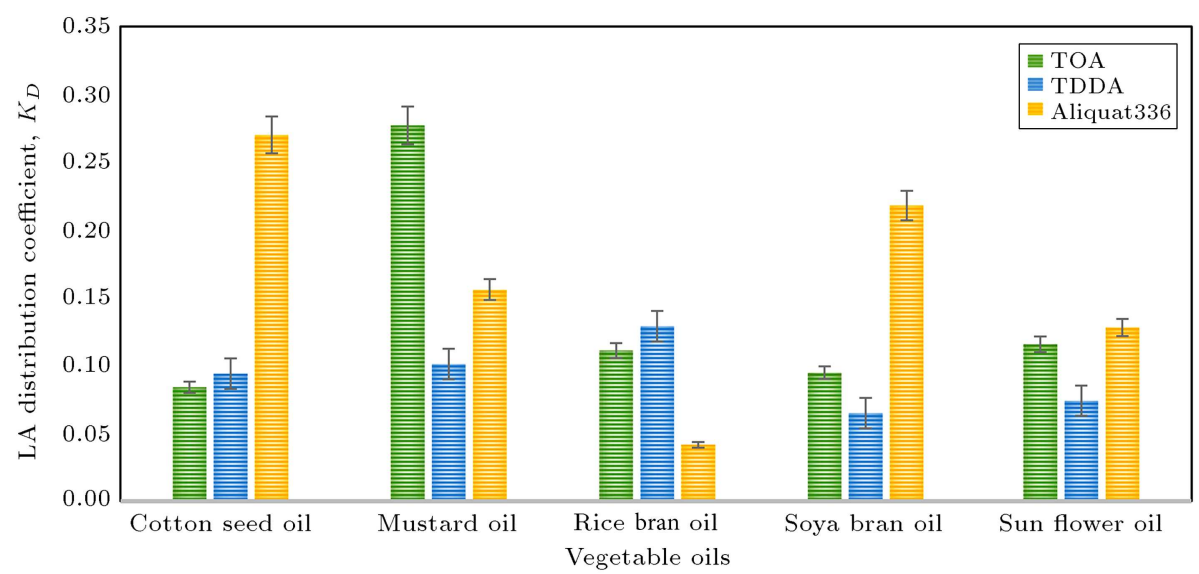

Figure 4. Effect of various extractants on the LA distribution coefficient $\left(K_{D}\right)$. [Experimental conditions: LA concentration: $0.05[\mathrm{M}]$, phase ratio: $1: 1(\mathrm{v} / \mathrm{v})$, agitation time: $120 \mathrm{~min}$, stirring speed: $100 \mathrm{rpm}$, temperature: $25^{\circ} \mathrm{C}$, phase separation time: $30 \mathrm{~min}$, feed phase volume: $10 \mathrm{~mL}$, and Organic phase volume: $10 \mathrm{~mL}(70 \%(\mathrm{v} / \mathrm{v})$ green diluent + $30 \%(\mathrm{v} / \mathrm{v})$ extractant)].

centration range (nearly up to 30 vol\%) since a higher concentration of these extractants is responsible for greater toxicity of microorganisms, raises the cost of the unit (to recover these extractants back), and also causes the formation of the third phase with the diluents [39]. Moreover, most of these extractants work well in acidic conditions only and with a rise in $\mathrm{pH}$ of the aqueous phase; further, $K_{D}$ reduces rapidly owing to the large availability of these extractants, which would not be present during the extraction process [35].

\subsubsection{The synergistic effect of extractants on the $L A$ distribution coefficient $\left(K_{D}\right)$}

Figure 5 depicts the combined effect of the extractants on the LA distribution coefficient. By using three extractants (TOA, TDDA, and Aliquat336) along with natural solvents, the combined effect of these extractants on $K_{D}$ was examined. The organic phase was articulated by combining these extractants (such as TOA+TDDA, TOA+Aliquat336, and TDDA+Aliquat336) and green solvents. An abrupt increment in the value of $K_{D}$ was observed due to the synergetic effect of the extractants. The combined effect of tertiary (TOA) and quaternary (Aliquat336) amines showed the highest value of LA distribution coefficient $\left(K_{D}=2.6 \pm 0.15\right)$ along with natural solvents. Among all green solvents, sunflower oil $\left(K_{D}=1.96 \pm 0.08\right.$ (with extractant) and $K_{D}=0.191 \pm$ 0.009 (without extractant)) and soya bean oil $\left(K_{D}=\right.$ $2.53 \pm 0.05$ ) (with extractant) and $K_{D}=0.129 \pm 0.006$ (without extractant)) showed the highest value of LA distribution coefficient. Therefore, on the basis of LA distribution coefficient, the two natural solvents (sunflower oil and soya bean oil) and synergistic extractant (TOA and Aliquat366) were chosen for further examining the consequences of other process variables on

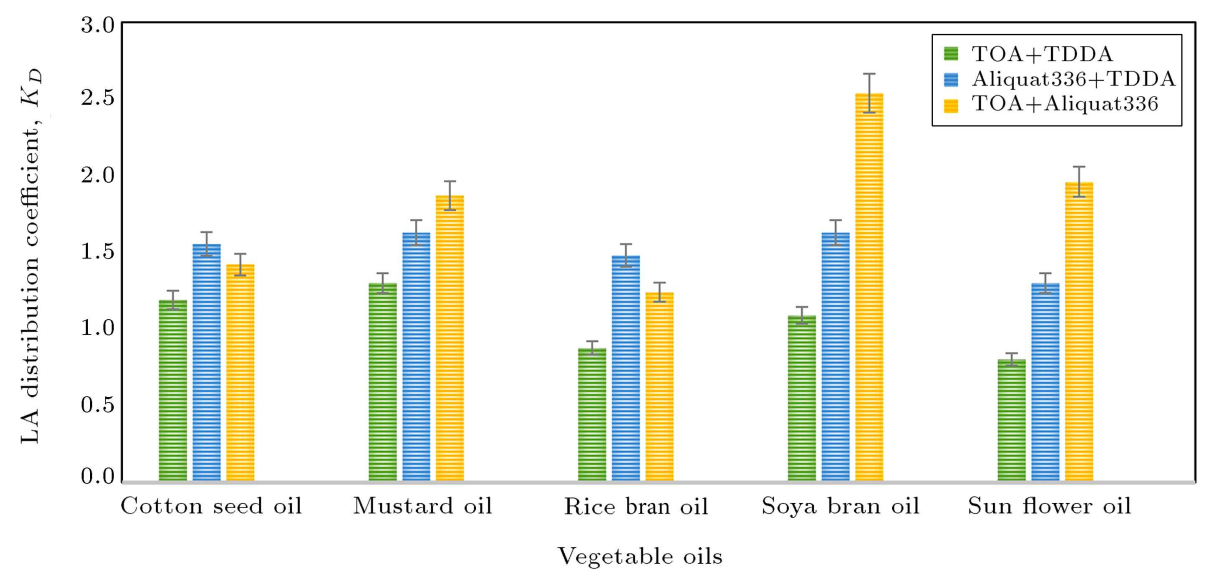

Figure 5. Effect of extractants on the LA distribution coefficient $\left(K_{D}\right)$. [Experimental conditions: LA concentration: $0.05[\mathrm{M}]$, phase ratio: $1: 1(\mathrm{v} / \mathrm{v})$, agitation time: $120 \mathrm{~min}$, stirring speed: $100 \mathrm{rpm}$, temperature: $25^{\circ} \mathrm{C}$, phase separation time: $30 \mathrm{~min}$, feed phase volume: $10 \mathrm{~mL}$, and organic phase volume: $10 \mathrm{~mL}(70 \%(\mathrm{v} / \mathrm{v})$ green diluent $+30 \%(\mathrm{v} / \mathrm{v})$ synergist extractant)]. 
the LA reactive extraction from the aqueous solution. Tertiary (TOA) and quaternary amines (Aliquat336) are considered as the most commonly used extractants due to their poor solubility in water without any decay in the extractant and, also, thermal stability [40]. Aliquat336 provides a high value of $K_{D}$ when the $\mathrm{pH}$ (meaning the maximum amount of the un-dissociated LA form available in the feed phase) of the external phase is below acid dissociation constant $\left(p K_{a}=3.86\right)$ since it extracts both the dissociated and undissociated forms of LA [16].

\subsubsection{Effect of organic solvent and extractant on the $L A$ distribution coefficient $\left(K_{D}\right)$}

Figure 6 shows the combined effect of both the organic solvent (butan-2-ol) and the synergistic effect of the extractants (TOA and Aliqaut336) on the LA distribution coefficient. Some pertinent physiochemical properties (viscous and corrosive in nature) of these extractants directly influence the LA distribution coefficient. For example, Aliquat336 is highly viscous in nature and reduces the rate of complex formation between the molecules of extractant and acid (solute), leading to a further reduction in the rate of transportation of solute (LA) molecules between phases [16]. Aliquat336 also tends to form the third phase when it is used alone. To reduce the properties of extractants and provide good solvation for the complex, these extractants have been used along with the organic solvent (butan-2-ol) during this study. These extractants (used individually) give a low value (as shown in Figure 4) of LA distribution coefficient $\left(K_{D}\right)$ owing to their non-polar nature [26]. It is appropriate to mention here that these extractants have low solubility in the aqueous phase due to their non-polar nature, hence leading to a reduction in water co-extraction [29]. Based on the observation in Figure 2, the selection of an organic solvent (butan2-ol) has been made, considering the value of LA

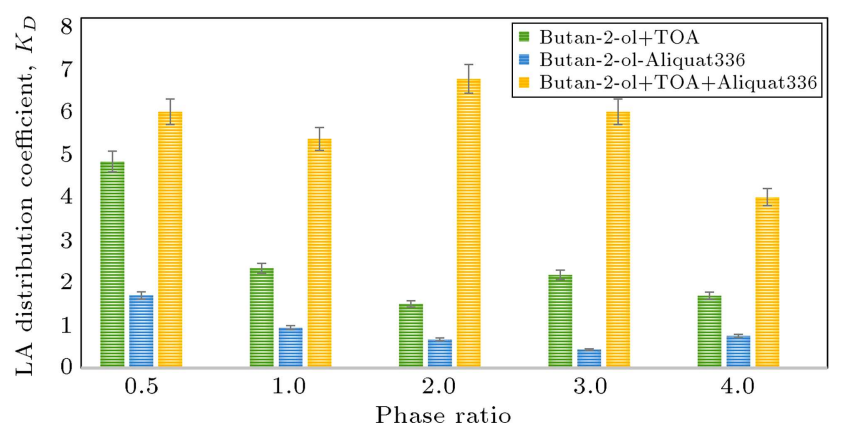

Figure 6. Effect of combination of diluent (butan-2-ol) and extractants on the LA distribution coefficient $\left(K_{D}\right)$. [Experimental conditions: LA concentration: 0.05 [M], agitation time: $120 \mathrm{~min}$, stirring speed: $100 \mathrm{rpm}$, temperature: $25^{\circ} \mathrm{C}$, phase separation time: $30 \mathrm{~min}$, and organic phase volume: $10 \mathrm{~mL}(30 \%(\mathrm{v} / \mathrm{v})$ extractant and $70 \%(\mathrm{v} / \mathrm{v})$ organic diluent (butan-2-ol))]. distribution coefficient $\left(K_{D}=1.175 \pm 0.07\right)$ and its pertinent properties (such as polarity, solubility (290 $\mathrm{g} / \mathrm{l}$ ), and dielectric constant (16.54)). The synergist extractant (as shown in Figure 5) exhibits better results for the distribution coefficient in the comparison with the individual extractant (as shown in Figure 4). The combined effect of butan-2-ol+TOA gives a value of LA distribution coefficient $\left(K_{D}=2.33 \pm 0.05\right)$ larger than that of butan-2-ol+Aliquat336 $\left(K_{D}=0.94 \pm\right.$ $0.009)$ for a phase ratio of $1(\mathrm{v} / \mathrm{v})$, because Aliquat336 is more viscous (1500 mpa.s at $30^{\circ} \mathrm{C}$ ) than TOA, increasing the interfacial mass transfer resistance for the transportation of LA from the aqueous solution to the organic solution [39]. The organic diluent (butan2 -ol) by itself gives a poor value of $K_{D}\left(K_{D}=1.175 \pm\right.$ $0.065)$; however, along with a synergistic mixture of extractants (TOA+Aliquat336), the LA distribution coefficient rises up to $5.36 \pm 0.06$ for an equal phase ratio $(1, \mathrm{v} / \mathrm{v})$.

Another implication of the obtained conclusion, which can also be made from Figure 6 about the consequence of the phase ratio on $K_{D}$, is that, with a rise in the phase ratio, distribution coefficient $\left(K_{D}\right)$ attains the maximum value $\left(K_{D}=6.77 \pm 0.05\right)$ for the value of the phase ratio of $2(\mathrm{v} / \mathrm{v})$. However, the further enhancement of the values of the phase ratio beyond its value of 2 leads to a decrement in distribution coefficient $\left(K_{D}\right)$, which may be due to the improper and deficient mixing of both phases, further lessening the tendency of complex formation; therefore, there is a decrease in the interfacial rate of mass transfer and, hence, distribution coefficient [26,41]. Sunflower and soya bean oils as green solvents (from Figure 5), butan2-ol as an organic diluent, and TOA and Aliquat336 as synergist extractants (from Figure 6) were chosen based on the values of the LA distribution coefficient.

\subsubsection{Effect of the phase ratio on the $L A$ distribution coefficient $\left(K_{D}\right)$}

The effect of the phase ratio (External Phase (EP): Organic Phase (OP)) on $K_{D}$ is shown in Figure 7 . The organic phase is composed of various constituents such as Butan-2-ol (organic diluent), sunflower oil and soya bean oil (natural solvents), TOA, and Aliquat336 (synergistic extractant); further to this, its volume was kept constant. The phase ratio varied from 0.5 to $4(\mathrm{v} / \mathrm{v})$ with a change in the aqueous phase volume. The effect of natural solvent on the LA distribution coefficient $\left(K_{D}=5.36 \pm 0.06\right.$ (without natural solvent, Figure 6 ), and $K_{D}=14 \pm 0.05$ (with natural solvent (sunflower oil), Figure 7 ), for equal phase ratio (1, $\mathrm{v} / \mathrm{v})$ ) is very important and significant. According to Figure 7 , with the enhancement of the phase ratio, the value of $K_{D}$ decreased due to the saturation of the organic phase with the LA concentration in the aqueous solution [39]. The optimum value $(1, \mathrm{v} / \mathrm{v})$ of the phase 


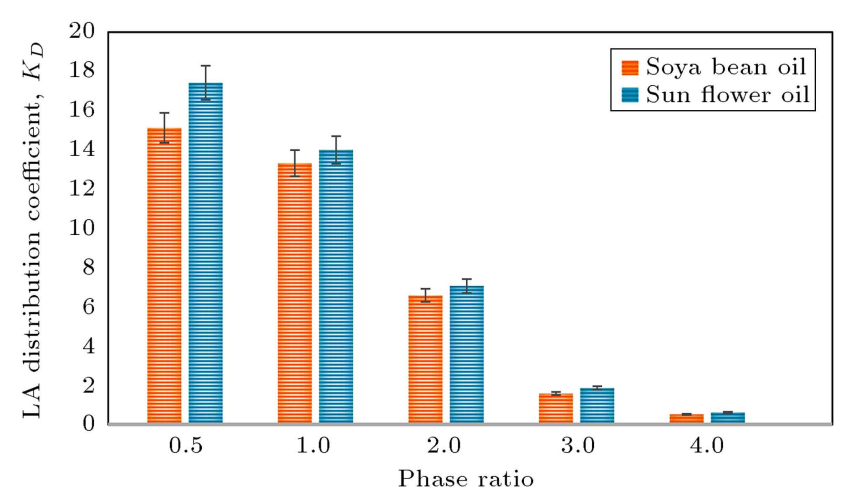

Figure 7. Effect of the phase ratio on the LA distribution coefficient $\left(K_{D}\right)$. [Experimental conditions: LA concentration: $0.05[\mathrm{M}]$, agitation time: $120 \mathrm{~min}$, stirring speed: $100 \mathrm{rpm}$, temperature: $25^{\circ} \mathrm{C}$, phase separation time: $30 \mathrm{~min}$, and organic phase volume: $10 \mathrm{~mL}(30 \%$ $(\mathrm{v} / \mathrm{v})$ synergist extractant (TOA + Aliquat 336$)$ and $70 \%$ $(\mathrm{v} / \mathrm{v})$ diluents $(35 \%(\mathrm{v} / \mathrm{v})$ butan-2-ol $+35 \%(\mathrm{v} / \mathrm{v})$ green diluent].

ratio has been chosen on the basis of the economy of the process and the appropriate/adequate mixing ability of both phases for obtaining a higher LA distribution coefficient. An abrupt increase in the LA distribution coefficient (for soya bean oil, $K_{D}=2.53 \pm 0.05$ (without an organic solvent), $K_{D}=13.33 \pm 0.07$ (with an organic solvent) and for sunflower oil $K_{D}=1.96 \pm$ 0.08 (without an organic solvent), $K_{D}=14 \pm 0.068$ (with an organic solvent)) was observed (Figure 7 ). This may result from the combined effect of both the extractants (synergistic effect of extractants) and the diluents (additional solvation of these natural solvents along with butan-2-ol) [39]. On the basis of results of Figure 7, sunflower oil as a green solvent was selected for further investigation of other process parameters.

\subsubsection{Effect of the solvent ratio on the $L A$ distribution coefficient $\left(K_{D}\right)$}

The effect of the solvent ratio (butan-2-ol: Sunflower oil) on $K_{D}$ is shown in Figure 8 . The amount of organic phase was kept constant; however, the ratio of both diluents in the organic phase for obtaining the maximum value of $K_{D}$ varied.

The organic phase is composed only of the diluents (butan-2-ol (organic solvent) and sunflower oil (natural solvents)). There was no synergist extractant (TOA+Aliquat336) present in the organic phase. The LA distribution coefficient was observed to be enhanced with a rise in the solvent ratio up to $4(\mathrm{v} / \mathrm{v})$; however, after that, the increment of LA distribution coefficient was not so significant due to the presence of a large amount of sunflower oil in the organic phase as it increased the viscosity of the organic phase, which further enhanced the interfacial mass transfer resistance between the phases $[26,42]$. With an increase in the amount of the organic solvent in the natural solvent,

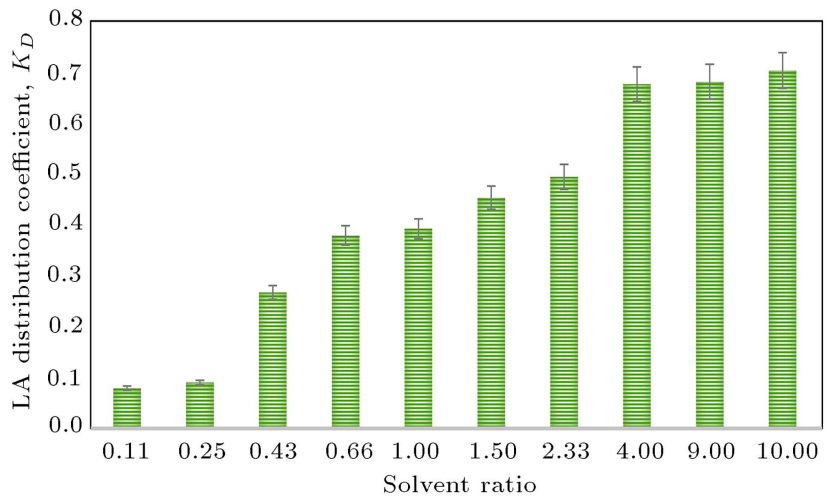

Figure 8. Effect of the solvent ratio (butan-2-ol: sunflower oil) on the LA distribution coefficient $\left(K_{D}\right)$. [Experimental conditions: LA concentration: 0.05 [M], phase ratio: 1:1 (v/v), agitation time: $120 \mathrm{~min}$, stirring speed: $100 \mathrm{rpm}$, temperature: $25^{\circ} \mathrm{C}$, phase separation time: $30 \mathrm{~min}$, feed phase volume: $10 \mathrm{~mL}$, and organic phase volume- $10 \mathrm{~mL}$ (butan-2-ol + sunflower oil)].

the value of LA distribution coefficient increased as it raised the loading rate (depends on the solubility) of the organic phase by increasing the rate of mass transfer, which may be due to a reduction in the viscosity of the organic phase [34]. The small values of the LA distribution coefficient mainly result from the inability of the synergist extractant, which usually plays a significant role in the chemical extraction processes.

\subsubsection{Effect of the solvent ratio along with the synergist extractant (TOA+Aliquat336) on the $L A$ distribution coefficient $\left(K_{D}\right)$}

Figure 9 shows the effect of the solvent ratio in the presence of synergist extractant on $K_{D}$. The organic

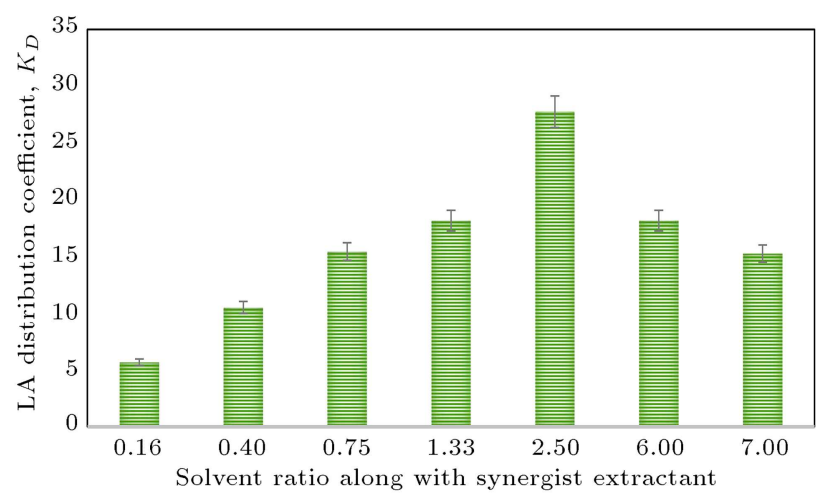

Figure 9. Effect of the solvent ratio (in presence of synergist extractant) on the LA distribution coefficient $\left(K_{D}\right)$. [Experimental conditions: LA concentration: $0.05[\mathrm{M}]$, phase ratio: $1: 1(\mathrm{v} / \mathrm{v})$, agitation time: $120 \mathrm{~min}$, stirring speed: $100 \mathrm{rpm}$, phase separation time: $30 \mathrm{~min}$, feed phase volume: $10 \mathrm{~mL}$, organic phase volume: $10 \mathrm{~mL}$ $(70 \%$ diluents (butan-2-ol + sunflower oil) $+30 \%(\mathrm{v} / \mathrm{v})$ synergist extractant (TOA $(15 \%(\mathrm{v} / \mathrm{v}))+$ Aliquat 336 $(15 \%(\mathrm{v} / \mathrm{v})))$, and temperature: $\left.25^{\circ} \mathrm{C}\right]$. 
Table 2. LA distribution coefficient $\left(K_{D}\right)$ and extraction efficiency $(\eta, \%)$ of the selected organic phase constituents.

\begin{tabular}{|c|c|c|c|}
\hline S. no & Organic phase constituents & $\begin{array}{l}\text { LA distribution } \\
\text { coefficient }\left(K_{D}\right)\end{array}$ & $\begin{array}{c}\text { Extraction efficiency } \\
(\eta, \%)\end{array}$ \\
\hline 1. & Butan-2-ol (10 mL) (polar diluent), Figure 2 & $1.175 \pm 0.05$ & $55.54 \pm 0.44$ \\
\hline 2. & Sunflower oil (10 mL) (green solvent), Figure 3 & $0.191 \pm 0.004$ & $16.03 \pm 0.32$ \\
\hline 3. & $\begin{array}{l}\text { Sunflower oil }(70 \%, \mathrm{v} / \mathrm{v})+\operatorname{Aliquat} 336(15 \%, \mathrm{v} / \mathrm{v}) \\
+ \text { TOA }(15 \%, \mathrm{v} / \mathrm{v}), \text { Figure } 5\end{array}$ & $1.96 \pm 0.08$ & $67.21 \pm 0.43$ \\
\hline 4. & $\begin{array}{l}\text { Butan-2-ol }(70 \%, \mathrm{v} / \mathrm{v})+\text { Aliquat336 }(15 \%, \mathrm{v} / \mathrm{v}) \\
+ \text { TOA }(15 \%, \mathrm{v} / \mathrm{v}), \text { Figure } 6\end{array}$ & $5.363 \pm 0.6$ & $84.92 \pm 0.48$ \\
\hline 5. & $\begin{array}{l}\text { Sunflower oil }(35 \%, \mathrm{v} / \mathrm{v})+\text { TOA }(15 \%, \mathrm{v} / \mathrm{v}) \\
+\operatorname{Aliquat336}(15 \%, \mathrm{v} / \mathrm{v})+\text { butan-2-ol }(35 \%, \mathrm{v} / \mathrm{v}), \text { Figure } 7\end{array}$ & $14 \pm 0.68$ & $93.83 \pm 0.53$ \\
\hline 6. & $\begin{array}{l}\text { Sunflower oil }(20 \%, \mathrm{v} / \mathrm{v})+\text { butan-2-ol }(50 \%, \mathrm{v} / \mathrm{v}) \\
+ \text { TOA }(15 \%, \mathrm{v} / \mathrm{v})+\text { Aliquat336 }(15 \%, \mathrm{v} / \mathrm{v}), \text { Figure } 9\end{array}$ & $27.75 \pm 0.22$ & $97.17 \pm 0.54$ \\
\hline
\end{tabular}

phase was constituted by various constituents (butan2-ol (as an organic diluent), sunflower oil (as a natural diluent), and TOA+Aliquat336 (as a synergist extractant)). The solvent ratio varied from 0.16 to $7(\mathrm{v} / \mathrm{v})$; however, the total volume of the organic phase and the volume of the synergist extractant in the organic phase were kept constant.

The presence of the synergist extractant in the organic phase increases the value of LA distribution coefficient due to a large increment in the complex (between acid and amine) formation tendency of the synergist extractant. With a rise in organic diluent volume (meaning an increase in solvation power for complexes) in the organic phase, LA distribution coefficient $\left(K_{D}\right)$ first increases up to the maximum value $\left(K_{D}=27.75 \pm 0.22\right.$, for solvent ratio of 2.5$)$; however, after that, it starts decreasing (from $K_{D}=27.75 \pm 0.22$ to $15.246 \pm 0.1$ ) due to a reduction in the amount of natural solvent, which has its own extractability and solvation power [43]. The presence of the large amount of natural solvent in the organic phase initially is responsible for the lower values of $K_{D}$. It may be due to the increased viscosity of the organic phase that decreases the rate of mass transfer of LA molecules from the aqueous to organic phase. The other plausible reason may be the high tendency of the third-phase formation during the initiation of reactive extraction. The $K_{D}$ and extraction efficiency (\%) of the selected organic phase constituents (butan-2-ol, sunflower oil, TOA, and Aliquat336) during the extraction of LA from aqueous solution are shown in Table 2.

\section{Conclusion}

This research work introduced the LA reactive extraction using amine-based extractants along with the natural solvents as an option for the LA extraction from the aqueous solution. The combination of organic solvent (butan-2-ol) and natural solvent (sunflower oil) showed the increment in $K_{D}$ values towards maximization. The presence of the synergist extractant (TOA and Aliquat336) in the organic phase gives higher $K_{D}$, compared to the individual extractants. The solvent ratio showed very significant effect on the LA distribution coefficient and extraction efficiency. The maximum values of LA distribution coefficient $\left(K_{D}=27.75 \pm 0.22\right)$ and extraction efficiency $(\eta=$ $97.17 \pm 0.54 \%)$ were obtained for the synergist extractant (TOA, $15 \%(\mathrm{v} / \mathrm{v})$ and Aliquat336, $15 \%(\mathrm{v} / \mathrm{v}))$, organic solvent (2-butanol, $50 \%(\mathrm{v} / \mathrm{v}))$, and natural solvent (sunflower oil, $20 \%(\mathrm{v} / \mathrm{v})$ ) with an initial LA concentration of $0.05[\mathrm{M}]$, phase ratio at $1.0(\mathrm{v} / \mathrm{v})$ upon stirring at $100 \mathrm{rpm}$ for $120 \mathrm{~min}$ at $25^{\circ} \mathrm{C}$. The findings of this present investigation on LA extraction using environmentally benign green solvents and synergist extractant will be very useful in reducing the amount 
of toxic and costly POS, which are frequently used in the previously existing reactive extraction technique. This research work will be beneficial for the incoming future both from economic and environmental points of view.

\section{Acknowledgment}

Authors are grateful to Sant Longowal Institute of Engineering and Technology, Longowal India for providing the lab facilities and all necessary assistance to complete this research work.

\section{References}

1. Vuković, A.D., Mladenović, D., Ivanović, J., Pejin, J., and Mojović, L. "Towards sustainability of lactic acid and poly-lactic acid polymers production", Renew. Sust. Energ. Rev., 108, pp. 238-252 (2019).

2. Thummarungsan, N., Pattavarakorn, D., and Sirivat, A. "Softened and flexible biodegradable poly (lactic acid) and its electromechanical properties for actuator application", J. Mech. Behav. Biomed. Mater., 64, pp. 31-42 (2016).

3. Pradhan, N., dIppolitoa, G., Dipasquale, L., Esposito, G., Panico, A., Lens, P.N.L., and Fontana, A. "Simultaneous synthesis of lactic acid and hydrogen from sugars via capnophilic lactic fermentation by Thermotoga neapolitana cf capnolactica", Biomass Bioenerg., 125, pp. 17-22 (2019).

4. Yan, L., Sun, Y.Q., and Xiu, Z.L. "Sugaring-out extraction coupled with fermentation of lactic acid", Sep. Purif. Technol., 161, pp. 152-158 (2016).

5. Zhang, K. and Yang, S.T. "In situ recovery of fumaric acid by intermittent adsorption with IRA-900 ion exchange resin for enhanced fumaric acid production by Rhizopus oryzae", Biochem. Eng. J., 96, pp. 38-45 (2015).

6. Garzon, C.S.L. and Straathof, A.J.J. "Recovery of carboxylic acids produced by fermentation", Biotechnol. Adv., 32, pp. 873-904 (2014).

7. Kumar, A., Thakur, A., and Panesar, P.S. "Lactic acid extraction using environmentally benign green emulsion ionic liquid membrane", J. Clean. Prod., 181, pp. 574-583 (2018).

8. Djas, M. and Henczka, M. "Reactive extraction of carboxylic acids using organic solvents and supercritical fluids: A review", Sep. Purif. Technol., 201, pp. 106119 (2018).

9. Nakano, S., Ugwu, C.U., and Tokiwa, Y. "Efficient production od D-(-)-lactic acid from broken rice by Lactobacillus delbrueckii using $\mathrm{Ca}(\mathrm{OH}) 2$ as a neutralizing agent", Bioresour. Technol., 104, pp. 791-794 (2012).

10. Li, X., Wang, S., Liu, Y., Jiang, L., Song, B., Li, M., Zeng, G., Tan, X., Cai, X., and Ding, Y. "Adsorption of $\mathrm{Cu}$ (II), $\mathrm{Pb}$ (II), and $\mathrm{Cd}$ (II) ions from acidic aqueous solutions by diethylenetriaminepentaacetic acidmodified magnetic graphene oxide", J. Chem. Eng. Data, 62, pp. 407-416 (2017).

11. Pérez, A.D., Barona, S.R., and Fontalvo, J. "Integration of a liquid membrane in Taylor flow regime with a fermentation by Lactobacillus casei ATCC 393 for insitu lactic acid removal", Chem. Eng. Process.: Process Intensif., 140, pp. 85-90 (2019).

12. Kumar, A., Thakur, A., and Panesar, P.S. "Statistical optimization of lactic acid extraction using green emulsion ionic liquid membrane (GEILM)", J. Environ. Chem. Eng., 6, pp. 1855-1864 (2018).

13. Li, Q.Z., Jiang, X.L., Feng, X.J., Wang, J.M., Sun, C., Zhang, H.B., Xian, M., and Liu, H.Z. "Recovery processes of organic acids from fermentation broths in the biomass-based industry", J. Microbiol. Biotechnol., 26, pp. 1-8 (2016).

14. Wasewar, K.L. "Reactive Extraction: An intensifying approach for carboxylic acid separation", Int. J. Chem. Eng. Appl., 3, pp. 249-255 (2012).

15. Roque, L., Escudero, I., and Benito, J.M. "Separation of sodium lactate from span 80 and SDS surfactants by ultrafiltration", Sep. Purif. Technol., 180, pp. 9098 (2017).

16. Datta, D., Kumar, S., and Uslu, H. "Status of the reactive extraction as a method of separation", $J$. Chem., 2015, pp. 1-16 (2015).

17. Xu, S., Lan, K., Li, J., He, T., and Hu, C. "Separation of lactic acid from synthetic solutions and the mixture directly derived from corn stover by aqueous two-phase extraction", Sep. Purif. Technol., 204, pp. 281-289 (2018).

18. Athankar, K.K., Varma, M.N., Shende, D.Z., Yoo, C.K., and Wasewar, K.L. "Reactive extraction of phenylacetic acid with tri-n-butyl phosphate in benzene, hexanol, and rice bran oil at $298 \mathrm{~K}$ ", J. Chem. Eng., 58, pp. 3240-3248 (2013).

19. Sulaiman, R.N.R. and Othman, N. "Synergistic green extraction of nickel ions from electroplating waste via mixtures of chelating and organophosphorus carrier", J. Hazard. Mater., 340, pp. 77-84 (2017).

20. Othman, N., Noah, N.F.M., Shu, L.Y., Ooi, Z.Y., Jusoh, N., Idroas, M., and Goto, M. "Easy removing of phenol from wastewater using vegetable oil-based organic solvent in emulsion liquid membrane process", Chin. J. Chem. Eng., 25, pp. 45-52 (2017).

21. Kumar, A., Thakur, A., and Panesar, P.S. "Stability analysis of environmentally benign green emulsion liquid membrane", J. Disper. Sci. Technol., 39, pp. 1510-1517 (2018).

22. Chang, S.H., Teng, T.T., Ismail, N., and Alkarkhi, A.F.M. "Selection of design parameters and optimization of operating parameters of soybean oil-based bulk liquid membrane for $\mathrm{Cu}$ (II) removal and recovery from aqueous solutions", J. Hazard. Mater., 190, pp. 197204 (2011). 
23. Sulaimana, R.R.N. and Othman, N. "Synergetic facilitated transport of nickel via supported liquid membrane process by a mixture of Di (2-ethylhexyl) phosphoric acid and n-octanol: Kinetic permeation study and approach for a green process", Chem. Eng. Process. - Process Intensifi., 134, pp. 9-19 (2018).

24. Wang, K., Chang, Z., Ma, Y., Lei, C., Jin, S., Wu, Y., Mahmood, I., Hua, C., and Liu, H. "Equilibrium study on reactive extraction of propionic acid with N1923 in different diluents", Fluid Phase Equilib., 278, pp. 103108 (2009).

25. Sarkar, R., Ray, S., and Basu, S. "Synergism in solvent extraction and solvent extraction kinetics", J. Chem. Biol. Phys. Sci., 4, pp. 3156-3181 (2014).

26. Kumar, A. and Thakur A. "Parametric optimization of green synergistic reactive extraction of lactic acid using trioctylamine, Aliquat336, and butan-2-ol in sunflower oil by response surface methodology", Chem. Eng. Commun., 206, pp. 1072-1086 (2019).

27. Zhang, Y., Zhang, T., Lv, G., Zhang, G., Liu, Y., and Zhang, W. "Synergistic extraction of vanadium (IV) in sulfuric acid media using a mixture of D2EHPA and EHEHPA", Hydrometallurgy, 166, pp. 87-93 (2016).

28. Kumar, A., Thakur, A., and Panesar, P.S. "A comparative study on experimental and response surface optimization of lactic acid synergistic extraction using green emulsion liquid membrane", Sep. Purif. Technol., 211, pp. 54-62 (2019).

29. Kumar, A., Thakur, A., and Panesar, P.S. "A review on emulsion liquid membrane (ELM) for the treatment of various industrial effluent streams", Rev. Environ. Sci. Bio/Technol., 18, pp. 153-182 (2019).

30. Kimberley, A.C. and Taylor, C.A. "A simple colorimetric assay for muramic acid and lactic acid", Appl. Biochem. Biotech., 56, pp. 49-58 (1996).

31. Waghmare, M.D., Wasewar, K.L., Sonawane, S.S., and Shende, D.Z. "Natural nontoxic solvents for recovery of picolinic acid by reactive extraction", Ind. Eng. Chem. Res., 50, pp. 13526-13537 (2011).

32. Jun, Y.S., Lee, E.Z., Huh, Y.S., Hong, Y.K., Hong, W.H., and Lee, S.Y. "Kinetic study for the extraction of succinic acid with TOA in fermentation broth; effects of $\mathrm{pH}$, salt and contaminated acid", Biochem. Eng. J., 36, pp. 8-13 (2007).

33. Keshav, A., Wasewar, K.L., and Chand, S. "Extraction of propionic acid with tri-n-octylamine in different diluents", Sep. Purif. Technol., 63, pp. 179-183 (2008).

34. Keshav, A., Wasewar, K.L., and Chand, S. "Recovery of propionic acid from an aqueous stream by reactive extraction: effect of diluents", Desalination, 244, pp. 12-23 (2009).

35. Yankov, D., Molinier, J., Albet, J., Malmary, G. and Kyuchoukov, G. "Lactic acid extraction from aqueous solutions with tri-n-octylamine dissolved in decanol and dodecane", Biochem. Eng. J., 21, pp. 6371 (2004).
36. Chawong, K., and Rattanaphanee, P. "Butan-1-ol as an extractant for lactic acid recovery", World Academy Sci. Eng. Technol., 5, pp. 1324-1327 (2011).

37. Mekade, R.S. and Deshpande, R.S. "Reactive extraction of succinic acid using natural solvent", J. Technol Adv. Sci. Res., 1, pp. 313-317 (2015).

38. Wasewar, K.L. "Separation of lactic acid: Recent advances", Chem. Biochem. Eng., 19, pp. 159-172 (2005).

39. Swarnkar, A., Keshav, A., Das, A.K., and Soni, A.B. "Modeling of the recovery of citric acid using aliquat336 in natural diluents", Int. J. Sci. Eng. Res., 2, pp. 2347-3878 (2014).

40. Juang, R.S., Huang, R.H., and Wu, R.T. "Separation of citric and lactic acids in aqueous solutions by solvent extraction and liquid membrane processes", J. Membr. Sci., 136, pp. 89-99 (1997).

41. Rastogi, N.K., and Chanukya, B.S. "Supported liquid membrane composed of tertiary and quaternary amine for the extraction of lactic acid", Int. J. Membrane. Sci. Technol., 2, pp. 19-28 (2015).

42. Harington, T., and Hossain, M. "Extraction of lactic acid into sunflower oil and its recovery into an aqueous solution", Desalination, 218, pp. 287-296 (2008).

43. Tuyun, A.F. and Uslu, H. "Extraction equilibria of picolinic acid from aqueous solution by tridodecylamine (TDA)", Desalination, 268, pp. 134-140 (2011).

\section{Biographies}

Anil Kumar is a full-time $\mathrm{PhD}$ Student (Senior Research Fellow) at the Department of Chemical Engineering, Sant Longowal Institute of Engineering and Technology (deemed to be University, under MHRD, Government of India), Longowal-148106, Sangrur. He received MTech from the same institute. He has published 7 research articles in the peer-reviewed journals (WOS) including a top publication in Google Scholar's Sustainable Development Category" (Journal of Cleaner Production). He has attended two international conferences and six national conferences and participated in many more short-term courses and other academic activities. He is also a life member of Biotechnology Research Society of India (BRSI) and Indian institute of Chemical Engineers (IIChE). His areas of interest are green chemical engineering, green extraction, application of green solvents instead of toxic and costly petroleum-based solvents in liquid membranes, separation and purification of low concentrated solutes (such as toxic metal ions and organic acids) from industrial waste streams, mathematical modeling, and process optimization.

Avinash Thakur is working as Professor and the Head of the Department of Chemical Engineering at Sant Longowal Institute of Engineering and Technology 
(deemed to be University: Established by Goverment of India), Longowal-148106, Punjab, India. He has 22 years of experience in teaching and research. Dr. Avinash Thakur has supervised $30 \mathrm{~B}$. Tech and $06 \mathrm{M}$. Tech Thesis and is currently supervising $02 \mathrm{PhD}$ Scholars. He is a life member of Biotechnology Research Society of India, Indian Society for Technical Education, etc. His articles have appeared in journals such as Waste and Biomass Valorization, Journal of Cleaner Production, International Journal of Food Engineering,
Separation and Purification Technology, Journal of Industrial and Engineering Chemistry, Biomass Conversion and Biorefinery, Reviews in Environmental Science and Bio/Technology, Journal of Dispersion Science and Technology, etc. His research is focused on the area of biochemical engineering and downstream separation processes, especially green solvent extraction and value addition of agro-industrial wastes. $\mathrm{He}$ has visited countries such as UK, Switzerland, New Zealand, and Australia for academic assignments. 